\title{
Accuracy of Self-Reported Physical Activity Levels in Obese Adolescents
}

\author{
Sarah A. Elliott, ${ }^{1,2}$ Kimberley A. Baxter, ${ }^{1}$ Peter S. W. Davies, ${ }^{1}$ and Helen Truby ${ }^{2}$ \\ ${ }^{1}$ Children's Nutrition Research Centre, Queensland Children's Medical Research Institute, Royal Children's Hospital, \\ The University of Queensland, Herston, QLD 4029, Australia \\ ${ }^{2}$ Department of Nutrition and Dietetics, Faculty of Medicine, Nursing and Health Sciences, Monash University, \\ Notting Hill, VIC 3168, Australia
}

Correspondence should be addressed to Sarah A. Elliott; sarah.alexandra.elliott@gmail.com

Received 2 June 2014; Revised 22 July 2014; Accepted 4 August 2014; Published 26 August 2014

Academic Editor: Johannes B. van Goudoever

Copyright (C) 2014 Sarah A. Elliott et al. This is an open access article distributed under the Creative Commons Attribution License, which permits unrestricted use, distribution, and reproduction in any medium, provided the original work is properly cited.

\begin{abstract}
Introduction. Self-reported measures of habitual physical activity rely completely on the respondent's ability to provide accurate information on their own physical activity behaviours. Our aim was to investigate if obese adolescents could accurately report their physical activity levels (PAL) using self-reported diaries. Methods. Total energy expenditure (TEE) was measured using doubly labelled water (DLW) and resting energy expenditure (REE) was measured via indirect calorimetry. Activity energy expenditure (AEE) and PAL values were derived from measured TEE and REE. Self-reported, four-day activity diaries were used to calculate daily MET values and averaged to give an estimated PAL value (ePAL). Results. Twenty-two obese adolescents, mean age $13.2 \pm$ 1.8 years, mean BMI $31.3 \pm 4.6 \mathrm{~kg} / \mathrm{m}^{2}$, completed the study. No significant differences between mean measured and estimated PAL values were observed $(1.37 \pm 0.13$ versus $1.40 \pm 0.34, P=0.74)$. Bland Altman analysis illustrated a significant relationship $(r=-0.76, P<0.05)$ between the two methods; thus the bias was not consistent across a range of physical activity levels, with the more inactive overreporting their physical activity. Conclusion. At an individual level, obese adolescents are unlikely to be able to provide an accurate estimation of their own activity.
\end{abstract}

\section{Introduction}

The accurate and reliable assessment of physical activity among children and adolescents is important for many reasons. Physical activity is often assessed in large population based studies to detect group changes in physical activity levels, estimate population prevalence and trends, and evaluate the efficacy of interventions which aim to alter physical activity levels. The assessment of physical activity can also be used to guide dietetic advice, by assisting with the calculation of individual energy requirements.

Numerous methods exist for the assessment of physical activity. Broadly, the various techniques can be grouped as self-report, observation, heart rate monitoring (HRM), motion sensors, and doubly labelled water (DLW), which measures total energy expenditure (TEE) over time [1]. While the DLW technique is considered the most accurate method available for the assessment of daily TEE, which includes energy spent in physical activity in free-living subjects, however, its high cost and demanding methodology render the DLW method unavailable for routine clinical use. Additionally, other techniques, such as HRM and motion sensors, also have methodological drawbacks [1]. Consequently, often pragmatic considerations such as cost and participant burden lead to self-report as the tool of choice. Diaries represent a low cost and time efficient way to record physical activity patterns, timing, and relative intensity of physical activity, compared with criterion measures [2].

Self-reported questionnaires are useful in large-scale studies, but they rely on the child (or parent) to recall physical activity behaviour information accurately. Numerous selfreported instruments are available, with several being used in children. The four major types are (i) self-administered recall, (ii) interview-administered recall, (iii) diaries, and (iiii) proxy reports [3].

While some studies have reported a $73.4 \%$ to $86.3 \%$ agreement between these instruments and direct observation, 
these techniques should be used cautiously in pediatric populations in which recalling such information may be difficult. More recent evidence of the reliability and validity of physical activity assessments in children has been examined by Kohl III et al. [4], who reported a low to moderate validity for self-reported measures of physical activity.

Evidence on the use of self-reported measures of physical activity in health children is contradictory. Sallis et al. [5] in 1993, suggested that physical activity recalls of children as young as the fifth grade are of adequate reliability and validity to use in research on physical activity in children. However, Arvidsson et al. [6] have documented that, in comparison to DLW measures of physical activity, the physical activity questionnaire for adolescents was not able to accurately predict physical activity in a group of Swedish adolescents. As a result of this conflicting evidence, Corder et al. [7], just recently, assessed the validity and reliability of four self-reports to assess physical activity and time spent at moderate and vigorous intensity physical activity in British young people between 4 and 17 years of age, against measures of DLW. The strength of association between questionnaire and criterion methods varied $(r=0.09$ to $r=0.46)$. While some questionnaires were able to accurately assess group-level physical activity, the error was large for individual-level estimates.

While there have been a variety of studies investigating the use of self-reported measure of physical activity in healthy children and adolescents, little evidence of the use of such tools is available in obese children and adolescents. Dated studies by Heitmann and Lissner [8] and Waxman and Stunkard [9] reported that obese boys were less active than nonobese boys at home, but there were no differences in their activities when they were in a playground. It was also suggested that self-recorded activity records suffered from the same potential compliance problems as self-reported dietary intake and thus should be compared with more direct measures of activity $[4,10]$.

The accuracy of physical activity diaries, as stated by Sallis et al. [5], is highly dependent on the cooperation of the subject. In healthy children and adults, diary based selfreported instruments can provide, with good participation compliance, accurate assessments of habitual physical activity level (PAL) values [11]. However, self-reported measures of activity are fraught with difficulties in obese adult populations, who tend to overreport activity and underreport dietary energy intake [12]. It is unknown if these reporting difficulties are also found in obese children and adolescents. Thus, the aim of this study was to assess how accurately obese children and adolescents self-report their PAL values and to quantify the energy expended during physical activity.

\section{Methods}

Participants were aged between 10.00 and 17.99 years with a body mass index (BMI) greater than the 90th percentile for age and sex [13]. Subjects were obese but otherwise healthy, free from psychiatric morbidity, and not taking any medications known to alter metabolism or body composition. The experimental protocol was approved by the Royal
Children's Hospital, Brisbane (2006/096), and the University of Queensland Human Ethics Committee (2007000797). Written informed assent and consent were obtained by all adolescents and their parents prior to the commencement of the study.

2.1. Anthropometry. Height was measured to the last completed millimetre using a wall-mounted stadiometer (Holtain Instruments Limited Crymych, UK). Weight was measured to the nearest $0.05 \mathrm{~kg}$ using calibrated electronic scales (Tanita BWB-600 Wedderburn Scales, Australia). Body mass index (BMI) was calculated (weight $(\mathrm{kg}) /$ height $\left(\mathrm{m}^{2}\right)$ ) and $Z$ scores (SD scores), for BMI, were calculated using the reference values for children from the Centers for Disease Control and Prevention [13]. Pubertal (Tanner [14]) stage was determined by a pediatrician.

2.2. Total Energy Expenditure. Total energy expenditure was measured using the DLW method as described in detail elsewhere [15]. A baseline urine sample was collected for the determination of the background isotope enrichment level. Subjects were then given an oral dose of DLW $\left({ }^{2} \mathrm{H}_{2} \mathrm{O}\right.$ and $\mathrm{H}_{2}{ }^{18} \mathrm{O}$ ), approximately $0.083 \mathrm{~g}^{2} \mathrm{H}_{2}$ (99.8 atom\% excess; Sigma Aldrich, Milwaukee, WI) and $2.083 \mathrm{~g}{ }^{18} \mathrm{O}$ (10 atom $\%$ excess; Taiyo Nippon Sanso, Yokogawa, Japan) per $\mathrm{kg}$ of body water. Spot urine samples were collected after the dose at $5 \mathrm{hr}$ and on ten consecutive days. Analysis of the isotopic enrichment was determined in duplicate with an Isoprime Dual Inlet Stable Isotope Ratio Mass Spectrometer (Isoprime Dual Inlet SIRM, MassLynx 4.0i Software, Isoprime, Manchester, UK) coupled in-line with a MultiprepGilson autosampler. Hydrogen analyses were done by a $3 \mathrm{hr}$ equilibration with hydrogen gas at $40^{\circ} \mathrm{C}$ using Hokko coils. Oxygen analyses were done by a $10 \mathrm{hr}$ equilibration with $\mathrm{CO}_{2}$ at $40^{\circ} \mathrm{C}$. All samples were analyzed in duplicate and laboratory standards were calibrated using the international suite of waters SMOW, SLAP, and GISP. Results were reported in \%o (delta per mil units) relative to SMOW. Total energy expenditure was calculated using the multipoint method. The ${ }^{2} \mathrm{H}_{2}$ and ${ }^{18} \mathrm{O}$ zero-time intercepts and elimination rates $(\mathrm{kd}$ and ko) were calculated using linear regression of the log of isotopic enrichments, relative to predose enrichment using postdose urine samples over the 10-day sample period. The zero-time intercepts were used to determine the dilution spaces at the time of the dose. Total body water (TBW) was then calculated using the ${ }^{2} \mathrm{H}_{2}$ and ${ }^{18} \mathrm{O}$ dilutions spaces $\left({ }^{2} \mathrm{H}\right.$ dilution space/1.04 and ${ }^{18} \mathrm{O}$ dilution space/1.01, resp.). The production rates of carbon dioxide $\left(\mathrm{rCO}_{2}\right)$ and water $\left(\mathrm{rH}_{2} \mathrm{O}\right)$ from the isotope elimination rates ( $\mathrm{kd}$ and $\mathrm{ko}$ ) and TBW were determined by the method of Wells et al. [16]. Oxygen consumption was then determined using the following equation:

$$
\begin{aligned}
& \text { Oxygen consumption }(\mathrm{l} / \mathrm{min}) \\
& =\frac{\text { carbon dioxide production }(\mathrm{l} / \mathrm{min})}{0.85} .
\end{aligned}
$$


TABLE 1: Physical characteristics of all subjects.

\begin{tabular}{lccc}
\hline & All $(n$ 22) & Boys $(n$ 11) & Girls $(n$ 11) \\
mean \pm SD & mean \pm SD & $13.00 \pm 1.5$ \\
\hline Age $(\mathrm{y})$. & $13.2 \pm 1.8$ & $13.4 \pm 2.4$ & $161.3 \pm 11.1$ \\
Height $(\mathrm{cm})$ & $161.9 \pm 12.1$ & $162.5 \pm 13.5$ & $0,18,36,0,46$ \\
Tanner stage $(\% 1,2,3,4$, and 5$)$ & $18,9,36,9,28$ & $36,0,37,18,9$ & $83.0 \pm 20.5$ \\
Weight $(\mathrm{kg})$ & $82.9 \pm 20.5$ & $82.8 \pm 21.6$ & $31.7 \pm 5.1$ \\
BMI $\left(\mathrm{kg} / \mathrm{m}^{2}\right)$ & $31.3 \pm 4.6$ & $31.0 \pm 4.22$ & $2.13 \pm 0.30$ \\
BMI $Z$ score & $2.16 \pm 0.33$ & $2.18 \pm 0.36$ & $2004 \pm 452$ \\
REE $(\mathrm{kcal} / 24 \mathrm{hr})$ & $2042 \pm 442$ & $2078 \pm 452$ & $2657 \pm 531$ \\
TEE $(\mathrm{kcal} / 24 \mathrm{hr})$ & $2846 \pm 995$ & $3018 \pm 1313$ & $387 \pm 26$ \\
AEE $(\mathrm{kcal} / 24 \mathrm{hr})$ & $519 \pm 452$ & $638 \pm 729$ & $1.36 \pm 0.27$ \\
PAL & $1.40 \pm 0.34$ & $1.39 \pm 0.40$ & $1.35 \pm 0.45$ \\
ePAL & $1.37 \pm 0.13$ & $3.1 \pm 0.1$ & $3.0 \pm 0.3$ \\
Active behaviour (hrs) & $3.0 \pm 0.1$ & $11.4 \pm 2.3$ & $10.1 \pm 2.1$ \\
Sedentary behaviour (hrs) & $10.7 \pm 2.0$ & & \\
\hline
\end{tabular}

ePAL, PAL estimated by diary.

Active behaviour was defined as any activity in which the MET value ranged from 3.5 to 5.0, such as playing outside and sports. Sedentary behaviour was defined as any activity in which the MET values ranged from 1.0 to 1.5 , such as going to school, transportation, and screen time.

A respiratory quotient of 0.85 was used for each subject, as this value is indicative of the catabolism of a mixed diet over a period of days [17]. Using the production rate of carbon dioxide and the consumption rate of oxygen, TEE was then calculated using Weir's equation [17]. Consider

$$
\begin{aligned}
\operatorname{TEE}(\mathrm{kcal} / 24 \mathrm{hrs}) & \\
= & 3.941 \times \mathrm{O}_{2} \text { consumption }(\mathrm{l} / \mathrm{day}) \\
& +1.106 \times \mathrm{CO}_{2} \text { production }(\mathrm{l} / \mathrm{day}) .
\end{aligned}
$$

2.3. Resting Energy Expenditure. Resting energy expenditure (REE) was measured via indirect calorimetry using a ventilated hood system with the subject resting supine after an overnight fast (Deltratrac II Metabolic Monitor, MBM200, Datex-Deltatrac, Datex-Engstrom Division, Helsinki, Finland). The calorimeter was calibrated with a reference gas mixture of $95.00 \% \mathrm{O}_{2}$ and $5.00 \% \mathrm{CO}_{2} . \mathrm{O}_{2}$ consumption and $\mathrm{CO}_{2}$ production were measured at one minute intervals for 30 minutes and averaged over the whole measurement period. The subjects were required to rest in a supine position for 20 minutes prior to the commencement of the test. The first five to ten minutes were excluded from the analysis to account for environmental adjustment by the subjects and gas adaptation in the hood. REE was calculated from the measured oxygen consumption and carbon dioxide production similar to TEE according to the formula by Weir [17].

By measuring both TEE and REE, we therefore derived a measured activity energy expenditure $(\mathrm{TEE}-\mathrm{REE}=\mathrm{AEE})$ or $\mathrm{PAL}$ values $(\mathrm{PAL}=\mathrm{TEE} / \mathrm{REE})$.

2.4. Physical Activity. Physical activity was measured via a four-day self-reported diary, using a simplified version of activity dairies as described by Bouchard et al. [18], in conjunction with the measurement period of TEE using
DLW. Diaries were completed on three week days and one weekend day [18]. Subjects were given verbal and written instructions with an example of how to complete the diary. Each day was divided into $96 \times 15$ minute intervals and the subjects were asked to record their activities on each day. On completion, these activities were categorised into nine levels according to their average energy costs, representing multiples of their respective metabolic equivalents (METs) assigned as per Ainsworth et al. [19, 20]. Total daily METs values were calculated and averaged to give a PAL value for each subject. At the end of the recording period, the diary was checked with a researcher for completeness and any clarification of recorded activities was sought from parents of the child participating. Compliance with completing the diary was $100 \%$ as subjects were required to return the diary at a scheduled appointment.

2.5. Statistical Analysis. Statistical computation was performed using the SPSS for Windows statistical package (Version 18.0; SPPS Inc, Chicago, IL). In order to evaluate the agreement between the two measurement instruments, Bland-Altman analysis was used [21]. Level of significance was set at 5\% $(P<0.05)$ for all comparisons. Paired $t$ tests were used to compare measured and estimated TEE and PAL values. Results are expressed as means \pm SD.

\section{Results}

Twenty-two subjects, aged between 10.03 and 16.00 years, completed the study prior to entry into the Eat Smart program. All subjects were overweight with BMI $Z$ scores ranging from 1.43 to 2.61. Summary characteristics are presented in Table 1 . There were no statistically significant differences in any of the physical characteristics, TEE, or REE between boys and girls. Similarly, when TEE and REE were 


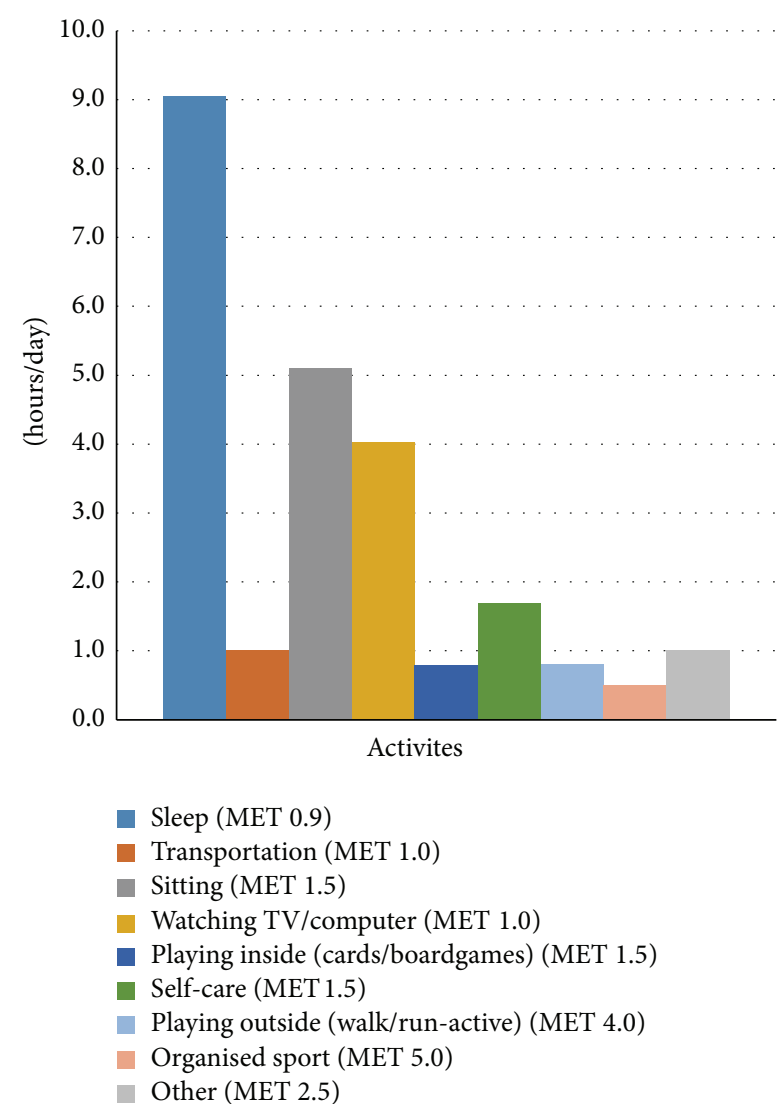

FIGURE 1: Time spent in physical activity estimated from physical activity diaries.

adjusted for FFM, using log-log regression, no significant gender differences were apparent.

The proportion of energy used for physical activity (AEE) was, on average, $20 \%$ of their daily TEE. Time spent in sedentary activity (METs $1-1.5$ ) occupied $45 \%$ of the day, while time spent in activity rated between 3.5 and 5.5 METs (i.e., playing outside and organised sport) occupied only $13 \%$ of the day. Figure 1 shows the hours spent in each physical activity diary category per day.

The group as a whole were sedentary, with girls reporting on average 4.7 hours per day of "screen time" and boys 3 hours per day. At a group level, there was no statistically significant difference between mean measured and mean estimated PAL values $(1.37 \pm 0.13$ versus $1.40 \pm 0.34$, resp., $P=0.74)$. A Bland-Altman analysis illustrated a significant relationship $(r=-0.76, P \leq 0.05)$ between the difference and the mean and between the two methods, demonstrating that the bias $(-0.01 \pm 0.39)$ was not consistent across the range of PAL values (Figure 2). Subjects with a low measured PAL tended to overreport their activity, while those with a higher measured PAL underreported their activity using the diary.

\section{Discussion}

Self-reported questionnaires are considered a useful tool to obtain qualitative data relating to habitual physical activity in

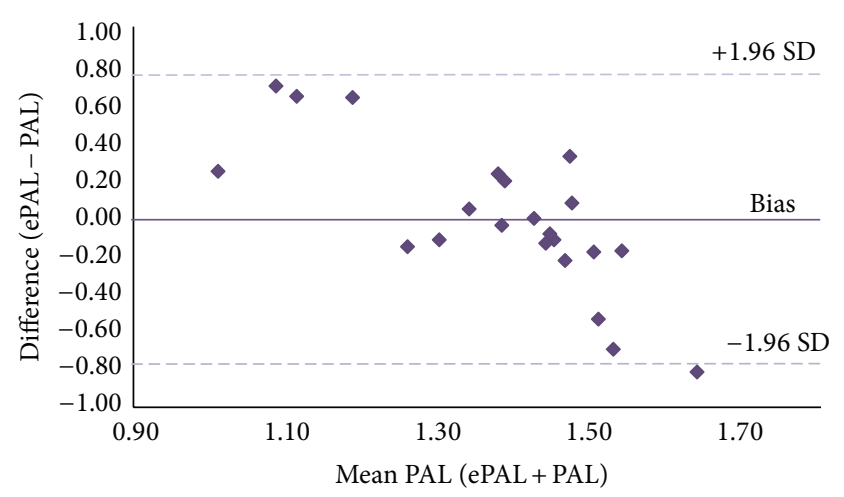

Figure 2: Bland-Altman ePAL. The Bland-Altman representation of the mean difference between estimated PAL values self-reported from physical activity diaries (ePAL) and measured PAL values obtained from measurements of TEE and REE (PAL = TEE/REE), in 22 obese children and adolescents.

children and adolescents. Physical activity diaries are often more economical and can provide information on the types and perceived intensity of activity not recorded from more objective measurement methods, such as accelerometers. While many physical activity diaries for the estimation of PAL values have been validated in healthy adults and children [22, 23], the use of these diaries to estimate PAL values in obese children and adolescents has not been previously reported.

In this present study, we compared estimated PAL values via self-reported diaries against energy expenditure measured via the reference DLW technique. Our findings show that obese adolescents tend to overestimate their PAL values when self-reporting their physical activity behaviours. At a group level, no statistically significant difference between measured and self-reported PAL values was observed. However, when determining the accuracy of these diaries to estimate PAL values using a Bland-Altman plot, correlation of significant magnitude was illustrated. Subjects with a low measured PAL tended to overreport their physical activity, following similar reporting patterns to obese adults [12].

Although in the presence of obesity the usefulness of self-reported measures of activity has been questioned, with obese adults shown to overreport their activity [24], many practitioners still utilise self-reported measures of activity to guide their choice of PAL value for the estimation of energy requirements.

The physical activity compendium developed by Ainsworth et al. [20], in 2002, was designed to facilitate the coding of physical activity diaries for the estimation of PAL values and provides activity codes and MET intensities for use in adults. Ridley and Olds [24] reported that using adult MET values was the most accurate assignment technique of energy costs to children's activities [25, 26], yet the energy cost of activity in obese children and adolescents may well be different. As mentioned previously, REE depends mainly on FFM, and as a result, in populations where FFM is altered, MET energy equivalents may vary significantly from the original $\mathrm{kcal} / \mathrm{kg} / \mathrm{hour}$ point of reference, as suggested by Ainsworth et al. [20]. 
A study by Ekelund et al. [27], investigating whether the intensity and duration of physical activity differed between obese and normal weight adolescents, has suggested that in obese children and adolescents the energy cost of any given physical activity is greater than in nonobese individuals. Moreover, Goran et al. [28] infer that perhaps the time spent in physical activity may be a more significant factor than energy expenditure attributable to physical activity, in the maintenance of energy balance.

The results from the present study, using a direct measure of physical activity, disagree with the findings of Goran et al. [28] and suggest that not only the amount of time spent participating in physical activity but also AEE might be associated with obesity and its development in children and adolescents. The mean PAL values for both boys (1.43) and girls (1.36) in the present study were much lower than the values previously reported in studies of children of similar ages [29-32]. In the current study, the mean values for AEE as a percentage of TEE $(23.5 \%$ in males and $16.2 \%$ in females) were lower than those reported by Ekelund et al. [27] (38.7\% in males and $36.3 \%$ in girls). The proportion of energy used for physical activity provided some insight as to whether physical activity, per se, could push the energy balance equation into deficit. The sample in this study used $20 \%$ of their daily energy expenditure for activity. In this sedentary population, a PAL value sufficient to push them into weight loss would require a substantial change in their activity. Schoeller [33] speculated that a relatively high PAL value of 1.75 is permissive for weight gain in a "society with unrestricted possibilities of excessive food consumption" $[27,33]$. A recent study by Metcalf et al. [34] also implied that fatness leads to inactivity not the other way around. Currently, there is no consensus on whether energy intake or lack of energy expenditure is the driver for childhood obesity [35]. There is a need to develop a low cost, practical, and accurate measure of physical activity in obese children and adolescents. The accurate measurement of physical activity is critical for determining energy requirements, current levels of physical activity, monitoring compliance with physical activity guidelines, and understanding the dose-response relationship between physical activity and health.

One of the main limitations of this study was that data were captured at a single time point, when activity was objectively measured using DLW; hence, no data on reproducibility are available. Furthermore, the inference that subjects with a PAL value underreported their level of physical activity as demonstrated in Figure 2 needs to be interpreted with caution. While a significant trend was apparent as suggestive of the correlation between the mean and difference of the two methods, the group as a whole were very sedentary. Approximately $90 \%$ of subjects had a PAL value of less than 1.6. A "higher" observed PAL value may be because TEE was higher, due to the energy cost of activity being higher in obese, so whilst they do not think they are very active, the activity they do perform, cost more energy.

Conversely, given the poor performance of self-report, one would question the need of such investigation. The present study was also limited by its cross-sectional design. Thus, we cannot draw any conclusions as to whether an inactive lifestyle causes obesity or whether obesity leads to a physically inactive lifestyle. Additionally, the small sample size due mainly in part to the high cost of the 18-oxygen isotope when dosing large individuals meant that this was not a true validation study. However, one of the strengths of this study was that the major components of energy expenditure (TEE and REE) were measured using reference techniques; thus valid assessments of energy expended in physical activity could be accurately assessed.

\section{Conclusion}

Sedentary, obese adolescents tend to overestimate their activity levels or perhaps underreport the time spent in sedentary activity, such as screen time. In clinical practice, the misreporting of PAL values could have deleterious effects on any weight management programme, as energy requirements would be significantly overestimated or underestimated. It is therefore recommended that the use of a four-day selfreported physical activity diary for the estimation of a PAL value in obese children and adolescents is unreliable for this purpose.

Estimating the true energy cost of physical activity remains a challenge. It is therefore important that physical activity records are accurate for use in individuals, to assist in the prediction of energy requirements. Physical activity records have the unique advantage of providing additional information on the types of activity and time devoted by individuals to specific activities. However, as sedentary obese children and adolescents tend to overreport their PAL values, objective measurement instruments or techniques need to be developed, to be used either in place of, or in combination, with diaries.

\section{Conflict of Interests}

The authors declare that there is no conflict of interests regarding the publication of this paper.

\section{Acknowledgments}

The authors are grateful for funding from University of Queensland and the ANZ Trustees funding.

\section{References}

[1] J. Dollman, A. D. Okely, L. Hardy, A. Timperio, J. Salmon, and A. P. Hills, "A hitchhiker's guide to assessing young people's physical activity: deciding what method to use," Journal of Science and Medicine in Sport, vol. 12, no. 5, pp. 518-525, 2009.

[2] E. C. Rush, M. E. Valencia, and L. D. Plank, "Validation of a 7-day physical activity diary against doubly-labelled water," Annals of Human Biology, vol. 35, no. 4, pp. 416-421, 2008.

[3] J. F. Sallis, "Self-report measures of children's physical activity," The Journal of School Health, vol. 61, no. 5, pp. 215-219, 1991.

[4] H. W. Kohl III, J. E. Fulton, and C. J. Caspersen, "Assessment of physical activity among children and adolescents: a review and synthesis," Preventive Medicine, vol. 31, no. 2, pp. S54-S76, 2000. 
[5] J. F. Sallis, M. J. Buono, J. J. Roby, F. G. Micale, and J. A. Nelson, "Seven-day recall and other physical activity self-reports in children and adolescents," Medicine and Science in Sports and Exercise, vol. 25, no. 1, pp. 99-108, 1993.

[6] D. Arvidsson, F. Slinde, and L. Hulthèn, "Physical activity questionnaire for adolescents validated against doubly labelled water," European Journal of Clinical Nutrition, vol. 59, no. 3, pp. 376-383, 2005.

[7] K. Corder, E. M. F. van Sluijs, A. Wright, P. Whincup, N. J. Wareham, and U. Ekelund, "Is it possible to assess free-living physical activity and energy expenditure in young people by self-report?" The American Journal of Clinical Nutrition, vol. 89, no. 3, pp. 862-870, 2009.

[8] B. L. Heitmann and L. Lissner, "Dietary underreporting by obese individuals-is it specific or non-specific?" British Medical Journal, vol. 311, no. 7011, pp. 986-989, 1995.

[9] M. Waxman and A. J. Stunkard, "Caloric intake and expenditure of obese boys," The Journal of Pediatrics, vol. 96, no. 2, pp. 187$193,1980$.

[10] C. W. Yu, R. Y. Sung, R. So et al., "Energy expenditure and physical activity of obese children: cross-sectional study.," Hong Kong Medical Journal, vol. 8, no. 5, pp. 313-317, 2002.

[11] C. Matthews, "Use of self-report instruments to assess physical activity," in Physical Activity Assessments for Health-Related Research, G. J. Welk, Ed., Human Kinetics Publishers, Champaign, Ill, USA, 2002.

[12] S. W. Lichtman, K. Pisarska, E. R. Berman et al., "Discrepancy between self-reported and actual caloric intake and exercise in obese subjects," The New England Journal of Medicine, vol. 327, no. 27I, pp. 1893-1898, 1992.

[13] R. Kuczmarski, C. Ogden, and S. Guo, "2000 CDC growth charts for the United States: methods and development. National Centre for Health Statistics," Vital Health Statistics, vol. 11, no. 246, pp. 1-190, 2000.

[14] J. Tanner, Growth at Adolescence, Blackwell Scientific, Oxford, UK, 2nd edition, 1962.

[15] P. Davies, "Measurement of energy expenditure and body composition using stable isotopes," Developmental Physiopathology and Clinics, vol. 2, no. 2, pp. 95-110, 1991.

[16] J. C. K. Wells, D. Haroun, J. E. Williams et al., "Evaluation of lean tissue density for use in air displacement plethysmography in obese children and adolescents," European Journal of Clinical Nutrition, vol. 65, no. 10, pp. 1094-1101, 2011.

[17] J. B. Weir, "New methods for calculating metabolic rate with special reference to protein metabolism," Journal of Physiology, vol. 109, no. 1-2, pp. 1-9, 1949.

[18] C. Bouchard, A. Tremblay, C. Leblanc, G. Lortie, R. Savard, and G. Thériault, "A method to assess energy expenditure in children and adults," The American Journal of Clinical Nutrition, vol. 37, no. 3, pp. 461-467, 1983.

[19] B. E. Ainsworth, W. L. Haskell, A. S. Leon et al., "Compendium of physical activities: classification of energy costs of human physical activities," Medicine and Science in Sports \& Exercise, vol. 25, no. 1, pp. 71-80, 1993.

[20] B. Ainsworth, W. L. Haskell, M. C. Whitt et al., "Compendium of physical activities: an update of activity codes and MET intensities," Medicine and Science in Sports and Exercise, vol. 32, supplement, pp. S498-S505, 2000.

[21] J. M. Bland and D. G. Altman, "Statistical methods for assessing agreement between two methods of clinical measurement," The Lancet, vol. 1, no. 8476, pp. 307-310, 1986.
[22] L.-. Bratteby, B. Sandhagen, H. Fan, and G. Samuelson, "A 7day activity diary for assessment of daily energy expenditure validated by the doubly labelled water method in adolescents," European Journal of Clinical Nutrition, vol. 51, no. 9, pp. 585-591, 1997.

[23] J. M. Conway, J. L. Seale, D. R. Jacobs Jr., M. L. Irwin, and B. E. Ainsworth, "Comparison of energy expenditure estimates from doubly labeled water, a physical activity questionnaire, and physical activity records," The American Journal of Clinical Nutrition, vol. 75, no. 3, pp. 519-525, 2002.

[24] K. Ridley and T. S. Olds, "Assigning energy costs to activities in children: a review and synthesis," Medicine and Science in Sports and Exercise, vol. 40, no. 8, pp. 1439-1446, 2008.

[25] B. Torun, "Energy requirements of children and adolescents," Public Health Nutrition, vol. 8, no. 7A, pp. 968-993, 2005.

[26] World Health Organisation, Energy and Protein Requirements. Report of a Joint FAO/WHO/UNU Expert Consultation, WHO Technical Report Series No. 724, World Health Organisation, Geneva, Switzerland, 1985.

[27] U. Ekelund, J. Åman, A. Yngve, C. Renman, K. Westerterp, and M. Sjöström, "Physical activity but not energy expenditure is reduced in obese adolescents: a case-control study," The American Journal of Clinical Nutrition, vol. 76, no. 5, pp. 935941, 2002.

[28] M. Goran, W. H. Carpenter, A. McGloin et al., "Energy expenditure in children of lean and obese parents," American Physiology Society, vol. 268, no. 5, part 1, pp. e917-e924, 1995.

[29] L. G. Bandini, D. A. Schoeller, and W. H. Dietz, "Energy expenditure in obese and nonobese adolescents," Pediatric Research, vol. 27, no. 2, pp. 198-203, 1990.

[30] U. Ekelund, M. Sjöströ, A. Yngve et al., "Physical activity assessed by activity monitor and doubly labeled water in children," Medicine and Science in Sports and Exercise, vol. 33, no. 2, pp. 275-281, 2001.

[31] D. J. Hoffman, A. L. Sawaya, W. A. Coward et al., "Energy expenditure of stunted and nonstunted boys and girls living in the shantytowns of Sao Paulo, Brazil," American Journal of Clinical Nutrition, vol. 72, no. 4, pp. 1025-1031, 2000.

[32] A. E. Black, "Physical activity levels from a meta-analysis of doubly labeled water studies for validating energy intake as measured by dietary assessment," Nutrition Reviews, vol. 54, no. 6, pp. 170-174, 1996.

[33] D. A. Schoeller, "Balancing energy expenditure and body weight," The American Journal of Clinical Nutrition, vol. 68, no. 4, pp. 956S-961S, 1998.

[34] B. S. Metcalf, J. Hosking, A. N. Jeffery, L. D. Voss, W. Henley, and T. J. Wilkin, "Fatness leads to inactivity, but inactivity does not lead to fatness: a longitudinal study in children (EarlyBird 45)," Archives of Disease in Childhood, vol. 96, no. 10, pp. 942-947, 2011.

[35] S. N. Bleich, R. Ku, and Y. C. Wang, "Relative contribution of energy intake and energy expenditure to childhood obesity: a review of the literature and directions for future research," International Journal of Obesity, vol. 35, no. 1, pp. 1-15, 2011. 


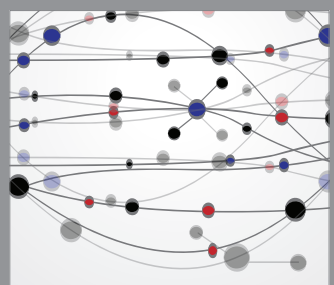

The Scientific World Journal
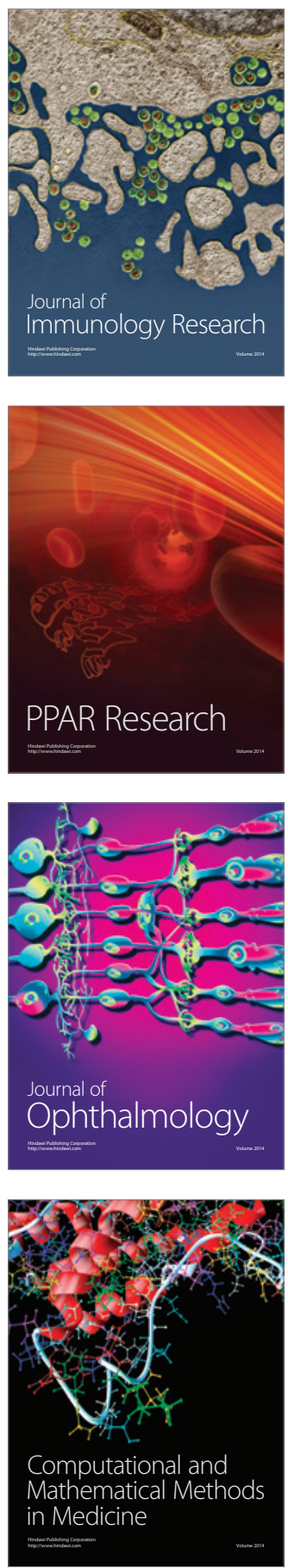

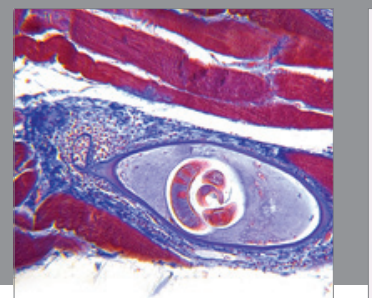

Gastroenterology

Research and Practice
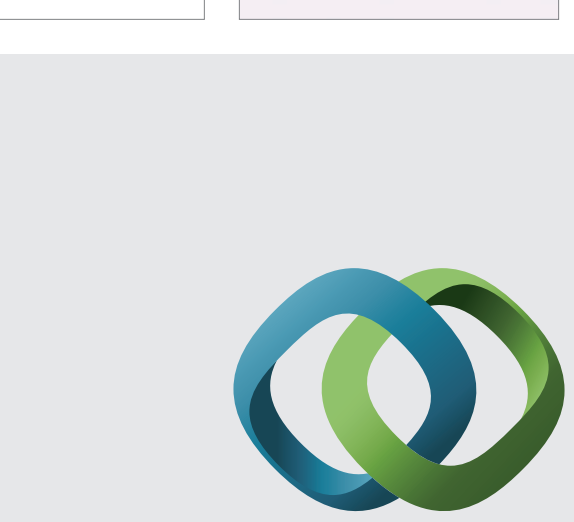

\section{Hindawi}

Submit your manuscripts at

http://www.hindawi.com
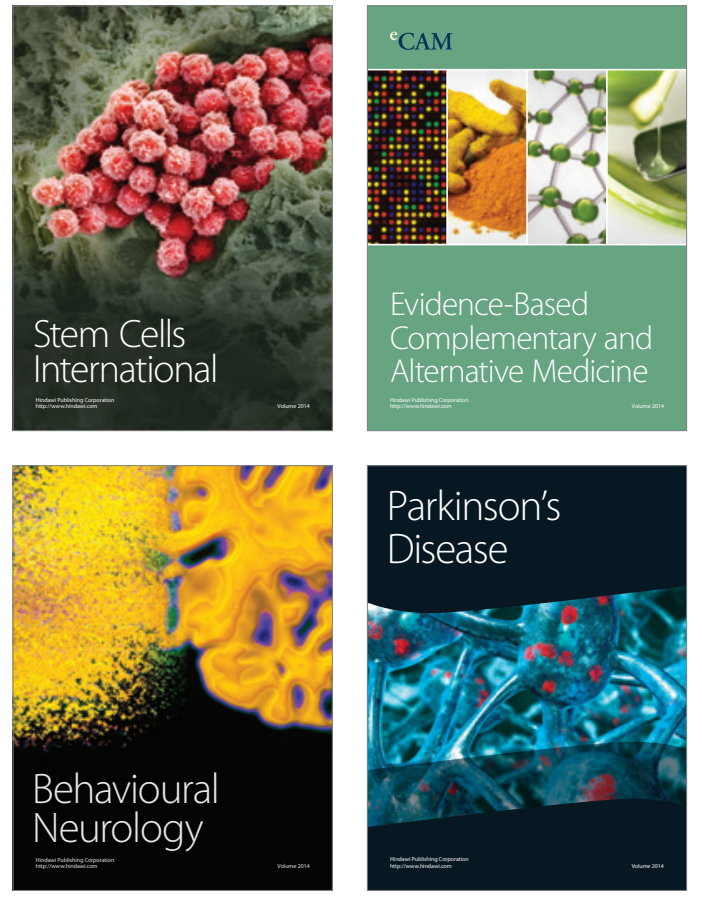
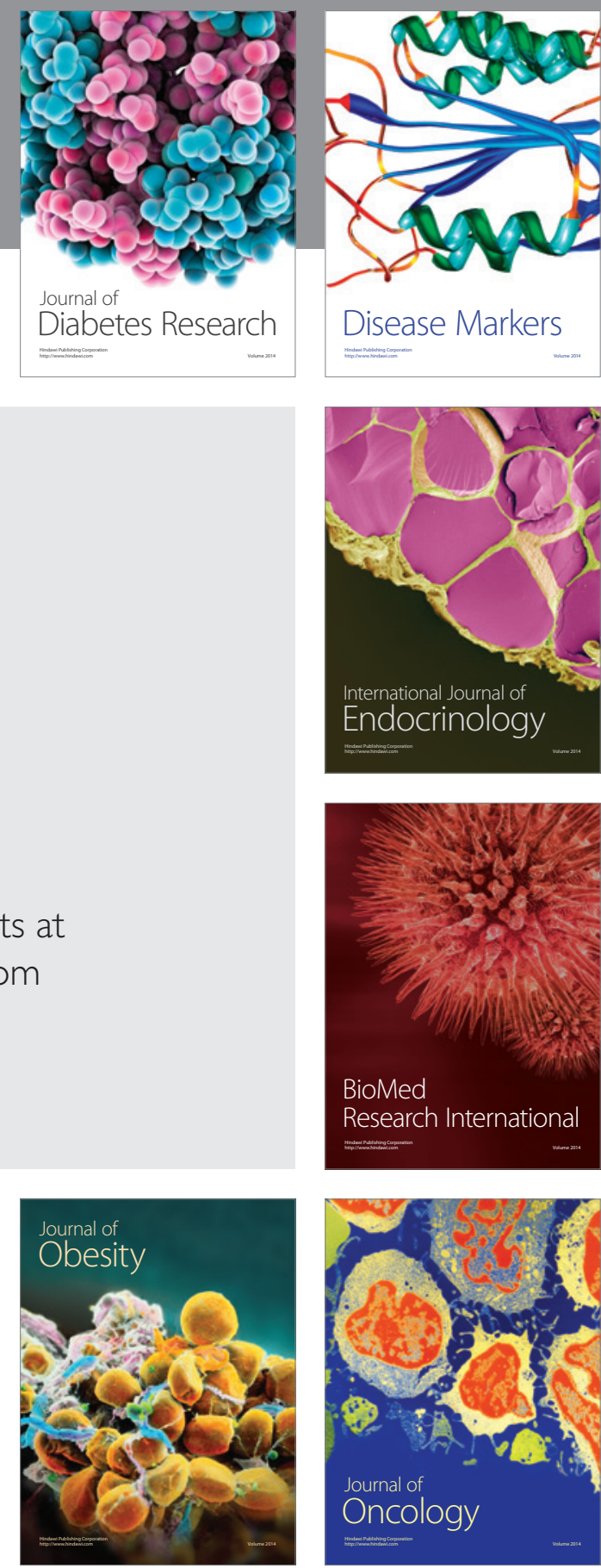

Disease Markers
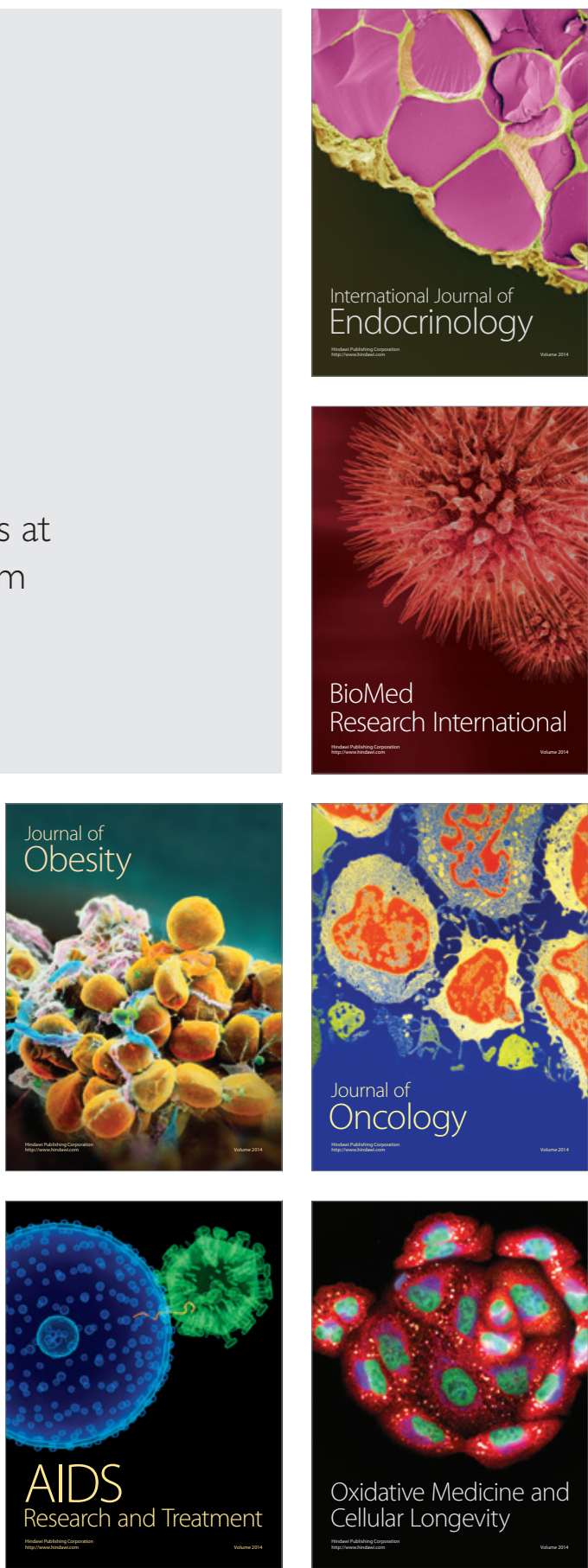